Since the double bond line of the 1.3.cyclohexadiene is more displaced towards smaller frequencies than the known line at $1584 \mathrm{~cm}^{-1}$ in benzene, and since it is near the latter in spite of the enormous differences in the saturation characteristics of the two compounds, the interpretation of the line $1584 \mathrm{~cm}^{-1}$ of benzene as being due to a double ethylenic bond in the ordinary meaning of organic chemistry would appear to be very doubtful.

$$
\text { G. B. Bonino. }
$$

R. Manzoni Ansidei.

Laboratorio di Chimica-Fisica

$$
\text { della R. Università, }
$$

Bologna.

1 Mem. Acc. Sci. Ist. Bologna Sess., May 27, 1934.

J. Chem. Soc., 85, 1403; 1904

3 Ber., 45, 809; 1912.

\section{Crystal Structure of some Alkali Tungsten Chlorides}

ABout twenty years ago, O. Olsson-Collenberg ${ }^{1}$ synthesised a series of alkali tungsten chlorides with trivalent tungsten of the general formula $\mathrm{M}_{3} \mathrm{~W}_{2} \mathrm{Cl}_{2}$. Later, Collenberg and Sandved ${ }^{2}$ found that water solutions of these compounds contain the complex ion $\mathrm{W}_{2} \mathrm{Cl}_{9}$. An X-ray analysis of these chlorides has now shown that this ion is present also in their crystals.

The ammonium, potassium, rubidium, eæsium and thallium compounds are all isomorphous and crystallise in the space-group $C_{6}^{2} h$. The unit cell of $\mathrm{K}_{3} \mathrm{~W}_{2} \mathrm{Cl}_{9}$ has the dimensions $a=7 \cdot 16 \mathrm{~A}$.; $c=16 \cdot 16 \mathrm{~A}$. and contains two molecules. Using Wyckoff's notation, the atomic positions are:

$2 \mathrm{~K}$ at $2(a), 6 \mathrm{Cl}$ at $6(h),\left(u_{3}=0.45, v_{3}=0.44\right)$. $4 \mathrm{~K}$ at $4(f),\left(u_{1}=0 \cdot 31\right) .12 \mathrm{Cl}$ at $12(i),(x=0 \cdot 12$, $y=0 \cdot 35, z=0 \cdot 16) . \quad 4 \mathrm{~W}$ at $4(f),\left(u_{2}=0 \cdot 076\right)$.

In this structure the $\mathrm{W}_{2} \mathrm{Cl}_{2}$ groups have the con-

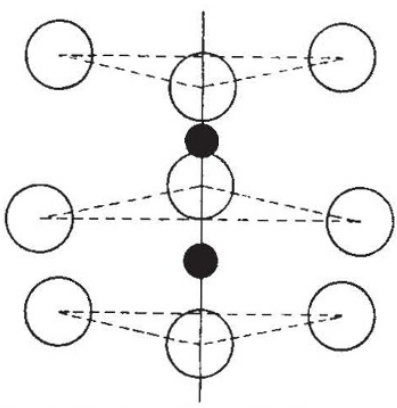

FIG. 1. Configuration of $\mathrm{W}_{\mathbf{2}} \mathrm{Cl}_{2}$ group in $\mathrm{M}_{\mathbf{2}} \mathrm{W}_{2} \mathrm{Cl}_{8}$. $\mathrm{O}, \mathrm{Cl} ; \mathrm{W}$, W. figuration shown in Fig. 1. Their centra form a lattice of the close. packed hexagonal type.

It is of interest to compare this structure with that of $\mathrm{Cs}_{3} \mathrm{As}_{2} \mathrm{Cl}_{9}$ recently determined by Hoard and Goldstein ${ }^{3}$. The latter contains no ions $\mathrm{As}_{2} \mathrm{Cl}_{9}$, and the complex arsenic chlorides seem thus to be of a different kind from the tungsten chlorides of analogous com. position.

A complete report of the structure determination will be given in the immediate future, and the investigation will be extended to embrace also the tungsten chlorides with metal-ammonia and partly organic cations.

Institute of General and

Cyrul Brosset.

Inorganic Chemistry,

University, Stockholm. March 1.

1 Thesis, Uppsala, 1914.

Z. anorg. allg. Chemie, 130, 1; 1923.

$3 \mathrm{~J}$. Chem. Phys., 3, 117 ; 1935.
The Spinels and the Cubic Sodium-Tungsten Bronzes as New Examples of Structures with Vacant Lattice Points

$\mathrm{X}-\mathrm{RAY}$ studies, carried out in this Institute, have shown that when the spinel, $\mathrm{MgO} \cdot \mathrm{Al}_{2} \mathrm{O}_{3}$, dissolves $\mathrm{Al}_{2} \mathrm{O}_{3}$, the oxygen excess is eaused by the occurrence of vacant points in the metal lattices. In accordance with this, $\gamma-\mathrm{Al}_{2} \mathrm{O}_{3}$, the unstable limit of these solid solutions, represents a spinel lattice where 1/9 of the metal positions are vacant.

In the same way it has been shown that when $\mathrm{Fe}_{3} \mathrm{O}_{4}$ is oxidised to $\gamma \cdot \mathrm{Fe}_{2} \mathrm{O}_{3}$, this process is accompanied by the occurrence of vacant points in the $\mathrm{Fe}$ lattice so that only $8 / 9$ of them are occupied in $\gamma-\mathrm{Fe}_{2} \mathrm{O}_{3}$. At the same time the lattice dimensions decrease. The presence of vacant points has been definitely shown by measurements of both the intensities of the interferences and the densities of the preparations.

The general formula of the sodium-tungsten bronzes has been shown to be $\mathrm{Na}_{x} \mathrm{WO}_{3}$. In the gold yellow bronze, $x$ is 1 and the cube edge $=3.850 \mathrm{~A}$. This bronze contains $\mathrm{W}^{+5}$ ions and crystallises in a complete perowskite lattice. The deepening of the colour from yellow through red to blue is accompanied by a continual decrease in sodium content and dimensions. With decreasing values of $x$, vacant points occur in the original $\mathrm{Na}$ lattice and in the blue bronze $(x=0.3-0.4, \quad a=3.813 \mathrm{~A}$. $)$, about two thirds of the original $\mathrm{Na}$ positions are empty. At the same time, $W^{+6}$ ions occur and the increasing amount of these ions is probably the cause of the deepening of the colour.

The above 'subtraction phases' represent, quite as much as the 'addition' or 'interstitial' phases, solid solutions with a variable number of atoms per unit cell. It is a mere matter of convenience if such a phase is termed a 'subtraction' or an 'addition' phase. In all cases where a variable number of atoms has been found, the structure is built up by large atoms or ions (in most cases anions, and especially oxygen ions). The atoms, which vary in number, are always comparatively small and placed in the interstices of the skeleton formed by the large atoms. A variation of their number is possible if the structure is of a non-polar type (hydrides, carbides, nitrides of many transition elements), if ions are substituted by other ions with another charge $\left(\mathrm{MgO} . \mathrm{Al}_{2} \mathrm{O}_{3} \rightarrow \gamma-\mathrm{Al}_{2} \mathrm{O}_{3}\right.$, tremolite $\rightarrow$ hormblende, $\beta$-cristobalite $\rightarrow \alpha$-carnegieite, $\mathrm{AgI} \rightarrow \mathrm{Ag}_{2} \mathrm{HgI}_{4}$ ), or if the lattice contains ions which are able to change their charge (especially in lattices containing transition elements, for example, $\mathrm{Fe}_{3} \mathrm{O}_{4} \rightarrow \gamma-\mathrm{Fe}_{2} \mathrm{O}_{3}$, the cubic $\mathrm{Na}$-W-bronzes).

More detailed reports of these investigations will be published elsewhere.

Institute of General and Inorganic Chemistry, University, Stockholm.

Feb. 28.

\section{Bio-Electric Transients during Fertilisation}

Is 1909 R. S. Lillie ${ }^{1}$ suggested that the activation of the unfertilised egg by a spermatozoon or by a parthenogenetic agent might involve the temporary depolarisation of the cell surface, the process being similar to that observed in stimulated nerve or muscle. This so-called 'physical' theory of fertilisation and parthenogenesis has been elaborated by Gray ${ }^{2}$, 